\title{
A patient with leptospirosis associated severe pulmonary haemorrhagic syndrome successfully managed with Extra Corporeal Membranous Oxygenation
}

\author{
Palliyaguruge NU, Egodage UK, Gunasinghe G, Harischandra DVT, Weerakoon RR \\ Teaching Hospital Karapitiya, Galle, SriLanka.
}

Correspondence: Dr. NU Palliyaguruge

e-mail: nupalliyaguruge@gmail.com

(iD https://orcid.org/0000-0002-3912-3273

\section{Introduction}

Leptospirosis is a zoonosis caused by Leptospira interrogans. Severe pulmonary haemorrhagic syndrome (SPHS) is the major cause of mortality in leptospirosis (1). Incidence of pulmonary haemorrhages in leptospirosis varies from $20-70 \%$ of patients (2). Contemporary theory suggests the pathogenesis of SPHS is immune mediated (1). Membranous depositions of linear immunoglobulins (IgA, IgG, IgM) and complement on alveolar surface may trigger fatal pulmonary haemorrhage (1). Here we describe a case of SPHS successfully managed with Veno-Venous Extra Corporeal Membranous Oxygenation (V-V ECMO) at Teaching Hospital Karapitiya.

\section{Case report}

A previously well, 48 year-old mason was transferred from a local hospital for the management of fever of 5 day duration. In addition, he had arthralgia, myalgia and reduced urine output for 12 hours. He did not have haemoptysis, cough, or shortness of breath. He gave a history of exposure to mud prior to the onset of fever. Examination revealed generalized muscle tenderness, conjunctival injection, icterus, pulse rate of $122 \mathrm{bpm}$, blood pressure of $90 / 60 \mathrm{mmHg}$, and respiratory rate of 26 cycles per minute. $\mathrm{SaO}_{2}$ on room air was $100 \%$. There was vesicular breathing and occasional scattered fine crepitations over both lung fields. Investigation findings are summarized in table 1.
Table 1: Lab findings of the patient on admission

\begin{tabular}{ll}
\hline Investigation & Result \\
\hline WBC & $7750 / \mu \mathrm{L}$ \\
Neutrophil & $86.2 \%$ \\
Platelets & $21000 / \mu \mathrm{L}$ \\
CRP & $299 \mathrm{mg} / \mathrm{dL}$ \\
Blood urca & $87 \mathrm{mg} / \mathrm{dL}$ \\
Scrum creatinine $(\mathrm{SCr})$ & $195 \mu \mathrm{mol} / \mathrm{L}$ \\
Serum sodium & $135 \mathrm{mmol} / \mathrm{L}$ \\
Serum potassium & $2.2 \mathrm{mmol} / \mathrm{L}$ \\
Total bilirubin & $157 \mu \mathrm{mol} / \mathrm{L}$ \\
Direct bilirubin & $127.5 \mu \mathrm{mol} / \mathrm{L}$ \\
UFR & red cells $4-6 / \mathrm{hpf}$ \\
\hline
\end{tabular}

ABG: $\mathrm{pH}$ 7.48; $\mathrm{PCO}_{2} 30 \mathrm{mmHg} ; \mathrm{PO}_{2} 72 \mathrm{mmHg}$. Chest radiograph was normal. Bedside ultrasound scan showed no free fluid or B lines but collapsible inferior vena cava. A presumptive diagnosis of leptospirpsis complicated with acute kidney injury, septic shock and possible pulmonary haemorrhages was made. Intravenous (IV) benzylpenicillin $2 \mathrm{MU}$ 6 hourly and oral doxycycline $100 \mathrm{mg} 12$ hourly were started. IV noradrenaline infusion was started because blood pressure did not improve with adequate fluid resuscitation. IV methylprednisolone 1g daily, IV tranexamic acid $1 \mathrm{~g} 8$ hourly and tranexamic acid nebulizations 8 hourly were also started suspecting pulmonary haemorrhages. Platelets were transfused to maintain platelet count $>50,000 / \mu \mathrm{L}$. Within next 12 hours patient became 
more tachypnoeic and bilateral end inspiratory fine crepitations became more prominent. He needed $\mathrm{O}_{2}$ via nasal prongs. Repeat chest radiograph showed bilateral diffuse alveolar infiltrates suggestive of pulmonary haemorrhages (Figure 1).

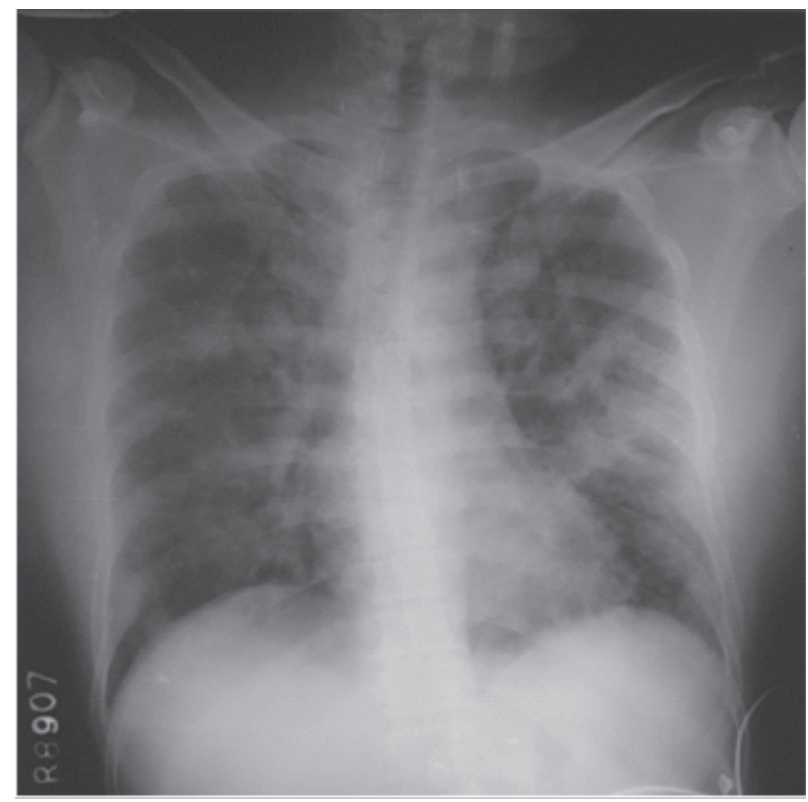

Figure 1: Chest radiograph; bilateral diffuse alveolar infiltrates suggestive of pulmonary haemorrhages.

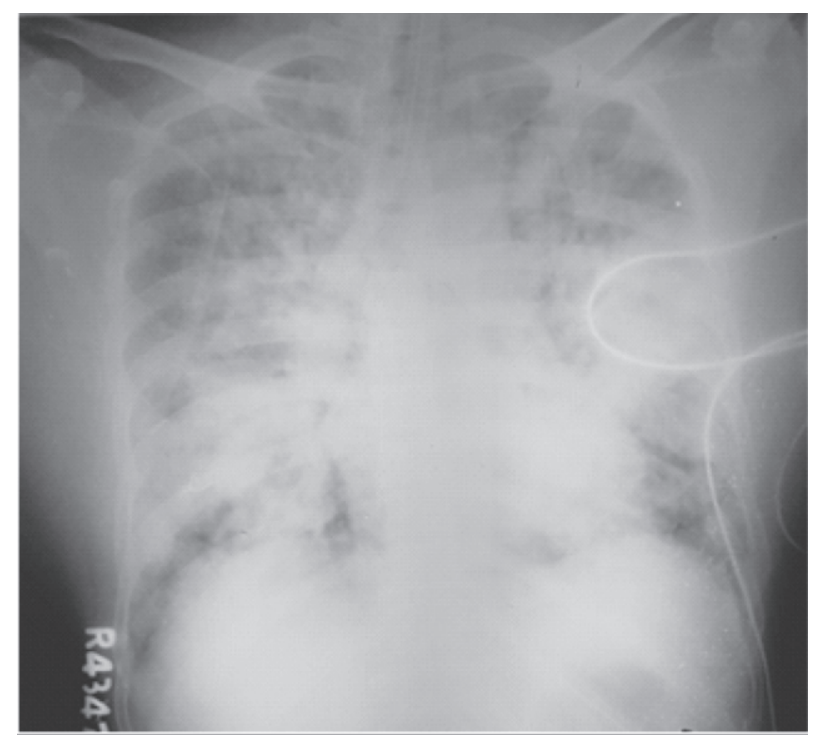

Figure 2: Chest radiograph; worsening pulmonary haemorrhages diffusely involving all zones of bilateral lung fields
Total plasma exchange (TPE) was started after a multidisciplinary team discussion among medical team, nephrologist and transfusion physician. The patient was transferred to medical ICU and CPAP was started. Bilateral alveolar infiltrates increased (Figure 2), haemoglobin dropped $(10.4 \mathrm{~g} / \mathrm{dL})$ and $\mathrm{ABG}$ deteriorated indicating worsening pulmonary haemorrhages.

Despite optimizing CPAP settings patient further deteriorated and we had to intubate him on the $3^{\text {rd }}$ day of admission. Bronchoscopy showed blood clots in the bronchial tree. On the $4^{\text {th }}$ day respiratory acidosis worsened (Figure 3) and Murray's acute lung injury score was 3. The patient was referred to cardiothoracic surgeon for ECMO. V-V ECMO was instituted via $20 \mathrm{Fr}$ and $28 \mathrm{Fr}$ percutaneous single lumen cannulae inserted into right internal jugular vein and right femoral vein respectively. ECMO settings are summarized in table 2 . Activated partial thromboplastin time was maintained between $190-$ 210 seconds with IV heparin infusion. During ECMO, mechanical ventilation was set at the lung rest settings. IV noradrenaline infusion titrated to maintain mean arterial pressure around $80 \mathrm{mmHg}$ and gradually weaned off. IV ceftriaxone $1 \mathrm{~g} 12$ hourly was added. Fever and inflammatory markers improved with treatment and serum creatinin became normal on the 5th day. IV immunoglobulin $0.4 \mathrm{~g} / \mathrm{kg}$ daily was given after each plasmapheresis. Methylprednisolone and immunoglobulin were omitted after completing 5 doses.

Alveolar infiltrates in chest radiograph started to improve on the $7^{\text {th }}$ day of admission (Figures $4 \& 5$ ).

Tidal volume improved from $240 \mathrm{ml}$ to $419 \mathrm{ml}$. Since chest radiograph, $\mathrm{ABG}$ and ventilator support gradually improved, trial off ECMO was performed. Oxygen flow through oxygenator was stopped at the $114^{\text {th }}$ hour. Since the trial off was successful, decannulation of ECMO was done at the $143^{\text {rd }}$ hour i.e.; $10^{\text {th }}$ day after admission.

The patient was extubated on the $14^{\text {th }}$ day and discharged from the hospital 8 days later. Pulmonary infiltrates were totally cleared from chest $\mathrm{x}$-ray on discharge. 
Table 2: ECMO settings

\begin{tabular}{lllllll}
\hline ECMO day & $\mathbf{1}$ & $\mathbf{2}$ & $\mathbf{3}$ & $\mathbf{4}$ & $\mathbf{5}$ & $\mathbf{6}$ \\
\hline Flow (L/min) & 4.8 & 5.0 & 4.65 & 4.93 & 3.8 & 3.2 \\
Gas Flow (L/min) & 5 & 10 & 11 & 12 & 4 & 2 \\
Motor RPM & 4000 & 4000 & 3800 & 3500 & 3400 & 3200 \\
\hline
\end{tabular}

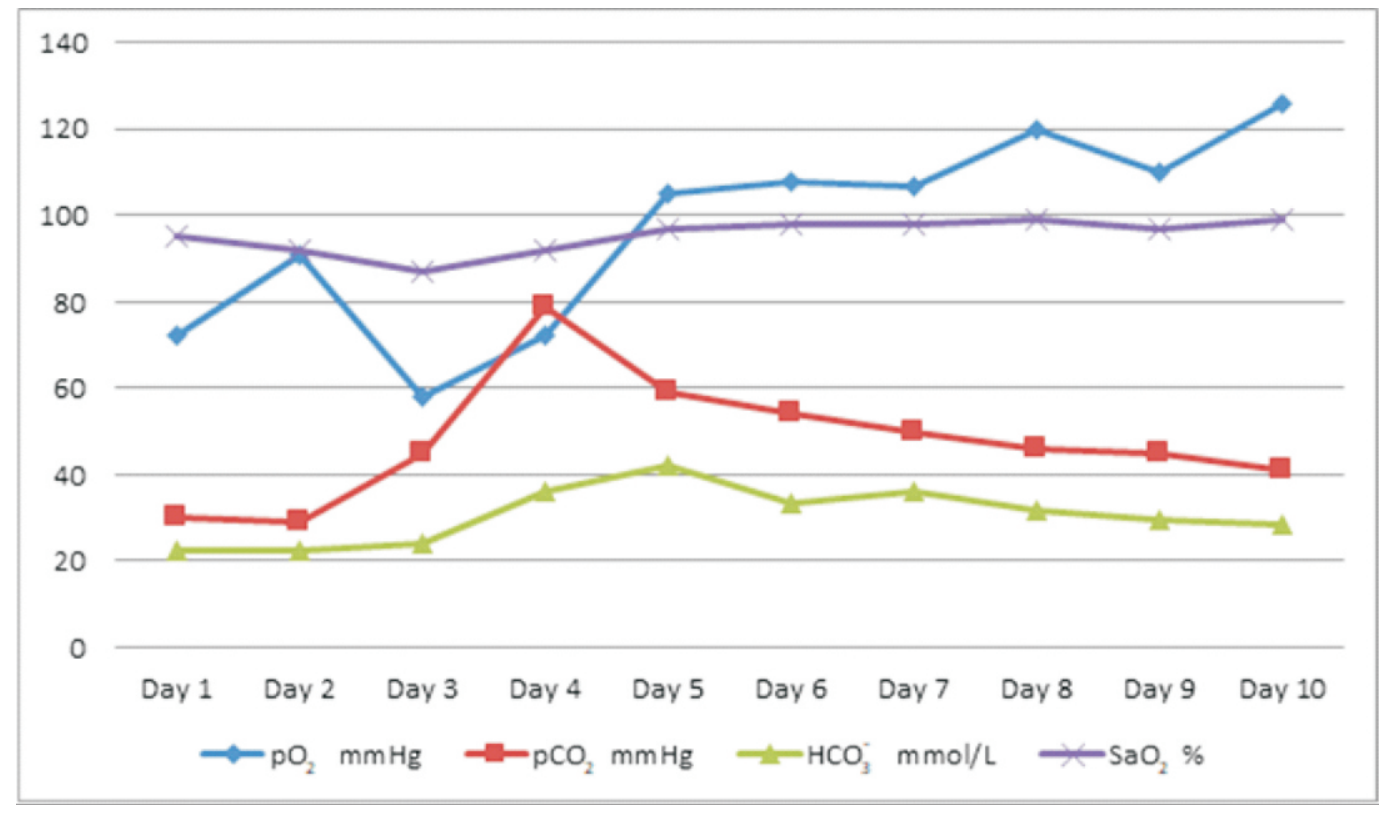

Figure 3: Graphic presentation of $A B G$ values
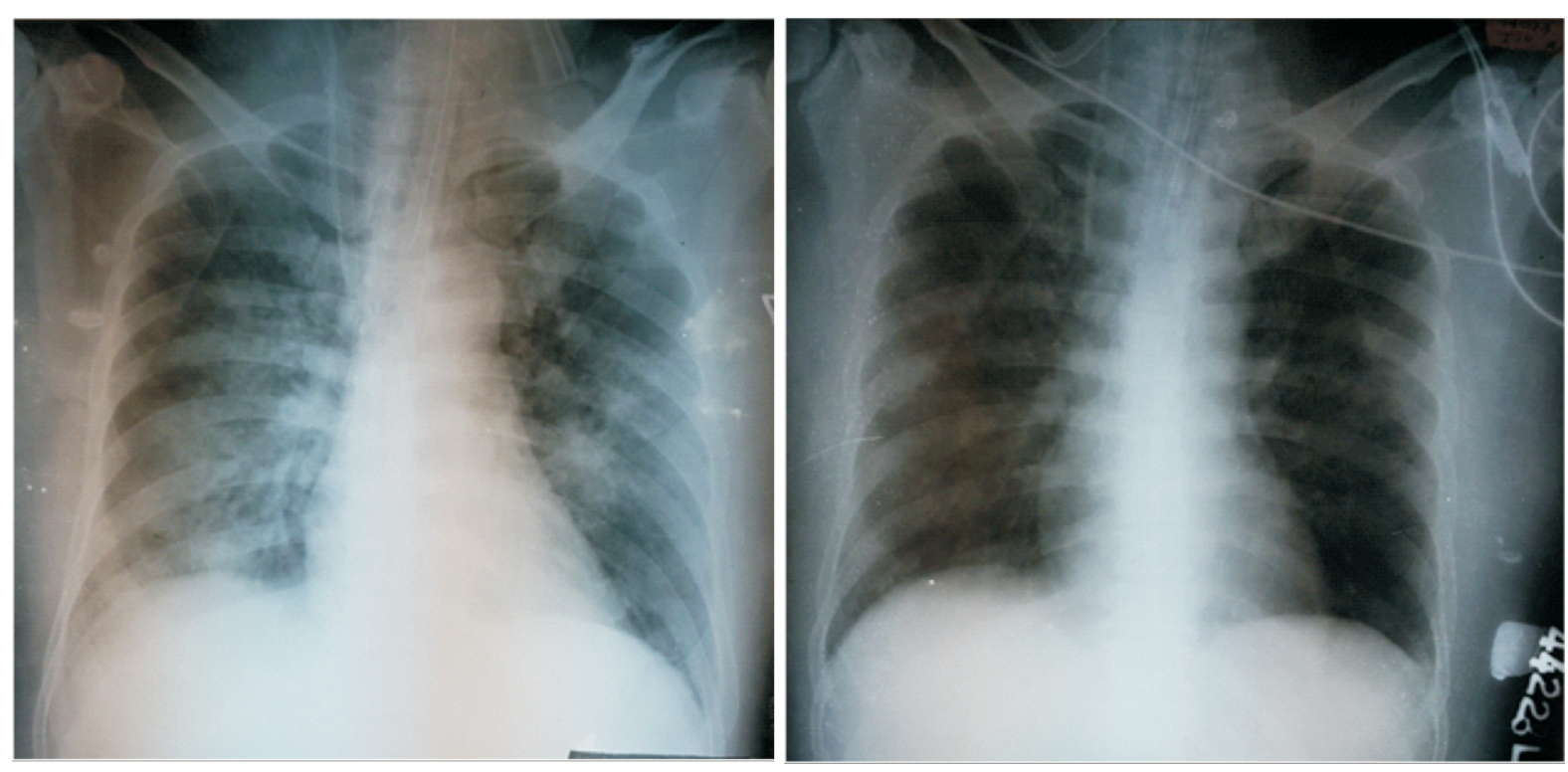

Figure 3 \& 4: Chest radiographs disappearance of pulmonary infiltrates 
The patient received a total of 7 packs of red cell concentrate and 34 packs of platelet concentrate. He never needed renal replacement therapy. ECG, troponin I and 2D Echocardiogram did not show features of myocarditis. MAT on days 10 and 24 after the onset of symptoms showed a fourfold or higher increase in antibody titres for Leptospira interrogans serovars Australis, Bangkinang, Bakeri, Cynopteri, and Patoc, confirming the diagnosis of leptospirosis. Lung function test performed 2 months after discharge was normal.

\section{Discussion}

Progressive lung injury increases the demand of pressure support which may in turn cause barotrauma and ventilator induced lung injury (7) leading to a vicious cycle. In addition high levels of PEEP may cause reduction in cardiac output and blood pressure (8). High-frequency oscillatory ventilation has been used to treat SPHS successfully when the response to maximal support with conventional mechanical ventilation (CMV) was poor. But the disadvantage was associated significant haemodynamic instability (3). ECMO is an alternative treatment which uses cardiopulmonary bypass technology to temporarily provide gas exchange (9). There are several case reports where SPHS was successfully treated with V-V ECMO (4-6). In our case we initiated V-V ECMO on the 8th day of illness, continued for 6 days and were able to extubate 4 days after the decannulation.

In conclusion, we suggest that V-V ECMO can be used as a treatment option for patients with leptospira SPHS and poorly responding to CMV. Since SPHS leading to ARDS is the major cause of death in leptospirosis, ECMO should be considered early when it is difficult to maintain oxygenation with CMV.

\section{Acknowledgements}

Authors gratefully acknowledge Dr. R. K. Firmin who shared his knowledge and experience in managing this patient and preparing the case report.

\section{References}

1. J Crodaa, Netoa, RA Brasila, C Pagliaria, AC Nicodemob, MIS Duartea. Leptospirosis pulmonary haemorrhage syndrome is associated with linear deposition of immunoglobulin and complement on the alveolar surface. Clinical Microbiology and Infection, 2010; 16(6): 593-9.

2. Carvalho CR, Bethlem EP. Pulmonary complications of leptospirosis. Clin Chest Med, 2002; 23(2): 469-78.

3. Nor MBM, Md Ralib A, Ibrahim NA, Abdul-Ghani MR. High frequency oscillatory ventilation in leptospirosis pulmonary haemorrhage syndrome: A case series study. Indian Journal of Critical Care Medicine, 2016; 20(6): 342-8.

4. Nao Umei and Shingo Ichiba. A Case of Leptospirosis associated severe pulmonary haemorrhagic syndrome successfully treated with venovenous extracorporeal membrane oxygenation. Case Reports in Critical Care, $2017 ; 5369267$.

5. Liao CY, Ben RJ, Wu HM, et al. Acute respiratory distress syndrome manifested by leptospirosis successfully treated by extracorporeal membrane oxygenation (ECMO). Internal Medicine, 2015; 54(22): 2943-6.

6. Arokianathan D, Trower K, Pooboni S, Sosnowski A, Moss P, Thaker H. Leptospirosis: A case report of a patient with pulmonary haemorrhage successfully managed with extra corporeal membrane oxygenation. The Journal of Infection, 2005; 50(2): 158-62.

7. $\mathrm{T}$ Whitehead, AS Slutsky. The pulmonary physician in critical care: Ventilator induced lung injury. Thorax 2002; 57: 635-42.

8. Thomas Luecke and Paolo Pelosi. Clinical review: Positive end-expiratory pressure and cardiac output. Crit Care, 2005; 9(6): 607-21.

9. Giles J Peek, Felicity Clemens, Diana Elbourne, Richard Firmin, Pollyanna Hardy, et al. CESAR: conventional ventilatory support vs extracorporeal membrane oxygenation for severe adult respiratory failure. $B M C$ Health Serv Res. 2006; 6: 163. 